\title{
On the relation of self-efficacy and coping with the experience of childbirth
}

\author{
María J Sánchez-Cunqueiro ${ }^{1}$, María Isabel Comeche ${ }^{2}$, Domingo Docampo*3 \\ ${ }^{1}$ Servizo Galego de Saúde, Centro de Saúde, Fernández Areal, Porriño, Spain \\ ${ }^{2}$ Universidad Nacional de Educación a Distancia, Facultad de Psicología, Juan del Rosal, Madrid, Spain \\ ${ }^{3}$ AtlanTTic Research Center, University of Vigo, Vigo, Spain
}

Received: November 3, 2017

Accepted: December 21, 2017 Online Published: January 8, 2018

DOI: $10.5430 /$ jnep.v8n6p48

URL: https://doi.org/10.5430/jnep.v8n6p48

\begin{abstract}
Objective: To analyze the relationship between self-efficacy expectancies, the use of coping behavior strategies during labor and satisfaction after childbirth.

Methods: A quantitative observational design was applied as part of a correlational study conducted in the maternity unit of a Hospital Complex that welcomes nearly 4,000 births each year at Vigo, Spain, between 2014 and 2015. A total of 276 low-risk pregnant women were recruited to undertake a self-assessment of their childbirth experience at two stages: within the last three months of pregnancy and within two weeks after labor. Data were collected through the Childbirth Self-Efficacy Inventory to measure self-efficacy expectancies as well as coping, along with a 6 items, 10-point Likert scale to measure satisfaction after childbirth.

Results and conclusions: Pearson product-moment correlation supported the positive association of self-efficacy expectancies scores with coping during labor. Multivariate regression analysis also revealed gains in satisfaction after childbirth associated with coping during labor. Women with larger scores in self-efficacy were found to use coping strategies during labor, had a more positive evaluation of the childbirth experience and showed significant gains in satisfaction after childbirth. The study supports the efforts of healthcare professionals to increase satisfaction with the childbirth experience by helping to enhance self-efficacy and coping in pregnant women.
\end{abstract}

Key Words: Self-efficacy, Coping, Midwifery, Pregnancy, Childbirth satisfaction, Coping behavior

\section{INTRODUCTION}

Childbirth, a life experience for women, has been a focus of midwifery literature for a number of years. Women's satisfaction with the childbirth experience has been associated with personal control during childbirth. ${ }^{[1]}$ A positive birth experience has been associated with an increased mother-child bond and maternal abilities, ${ }^{[2]}$ as well as with high levels of positive psychological functioning in the three months after childbirth. ${ }^{[3]}$ It has been reported, on the other hand, that an unsatisfactory childbirth experience may contribute to postnatal depression, ${ }^{[4]}$ a strong predictor of impairments in mother-infant bonding. ${ }^{[5]}$

To avoid negative experiences in childbirth it is essential to identify factors that contribute to a good experience, such as support, control and self-efficacy. ${ }^{[6-9]}$ In a systematic review of the literature on coping behaviors and coping styles in pregnancy, Guardino and Schetter found some evidence on the association of avoidant coping behaviors or styles and

*Correspondence: Domingo Docampo; Email: ddocampo@uvigo.es; Address: AtlanTTic Research Center, University of Vigo, Vigo, Spain. 
poor coping skills in general with postpartum depression, preterm birth, and infant development. ${ }^{[10]}$ Pregnant women have at their disposal a wide range of useful coping strategies for childbirth, such as acquiring information on the common procedures and expected sensations during birth, as well as cognitive, behavioral and physical strategies, involving the manipulation of cognitions, individual's overt actions or a person's physique; the use of the whole range of coping strategies seems to bear a beneficial effect on the experience of pain. ${ }^{[11]}$

The present study is based on Bandura's self-efficacy theory, a powerful construct to analyze coping behaviors. It is widely accepted that Bandura's theory of an individual's self-efficacy is a valid, and useful construct to predict and improve health status. The theory states that "expectations of personal efficacy determine whether coping behaviors will be initiated, how much effort will be expended, and how it will be sustained in the face of obstacles and adverse experiences". ${ }^{[12]}$ The theory has received broad attention in the Midwifery literature, particularly in connection with childbirth-related studies, since improving self-efficacy of mothers during prenatal services helps midwives working in partnership with women to provide better support, care and advice during pregnancy, labor and the postpartum period. A review of the quantitative literature on the effect of childbirth self-efficacy on perinatal outcomes reported that "increased childbirth self-efficacy is associated with a wide variety of improved perinatal outcomes". ${ }^{[13]}$

The choice of Bandura's construct for the analysis is rooted in its extensive use in childbirth studies. Manning and Wright began to analyze the role of self-efficacy in the women's ability to cope with childbirth. ${ }^{[14]}$ Since their seminal work, the evidence linking Self-efficacy theory with the development of women's confidence in coping with labor has only increased. ${ }^{[15]}$ It is now widely accepted that through the assessment of self-efficacy expectancies, it is possible to determine whether coping behaviors will be initiated and sustained when facing the pain associated with childbirth. ${ }^{[16]}$ Sinclair and O'Boyle reported that high levels of perceived self-efficacy contribute to increasing the motivation to sustain a behavior that women consider useful to coping with labor. ${ }^{[17]}$

A number of studies have reported an association of selfefficacy with anxiety, perceived support, the choice of type of birth, the development of depression, and well-being following childbirth. ${ }^{[16,18,19]}$ The factors influencing a woman's degree of satisfaction "have only been studied rudimentarily and are therefore incompletely understood". ${ }^{[20]}$ In particular, we are not aware of any previous investigation conducted

Published by Sciedu Press in Spain along the lines of the present study. Published work reporting studies carried out in other countries have focused primarily on the relationship between self-efficacy and pain in childbirth, anxiety or fear; development of posttraumatic stress symptoms or the choice of birth after previous Cesarean sections, particularly repeated C-sections. ${ }^{[21,22]}$ However, no study has been conducted to investigate the association of high levels of self-efficacy and coping during labor with maternal satisfaction after childbirth.

\section{MeTHODS}

The aim of this pilot study was to investigate the relationship between self-efficacy expectancies, the use of coping behavior strategies during labor and satisfaction after childbirth. The objectives were

(1) Examine the levels of self-efficacy expectancies and their association with the use of coping behaviors during labor.

(2) Examine the relationship of coping with labor and satisfaction after childbirth.

\subsection{Research design and setting}

A quantitative observational design as part of a correlational study was undertaken. A survey was conducted between 2014 and 2015 with the help of several members of the network of professional midwives from Public Health Services located around the city of Vigo (Spain). The participants were recruited from the maternity unit of the University Hospital Complex of Vigo, CHUVI. The Complex registers about 4,000 births per year.

\subsection{Participants}

Eligible mothers were primiparous and multiparous pregnant women within the last three months of a low-risk pregnancy (i.e., a pregnancy that is anticipated to be problem free). Lowrisk in this study refers to a woman with a Body Mass Index below 30 , carrying a full term single fetus in vertex presentation; a woman with no previous diagnosis of a condition that may pose a high risk of poor pregnancy outcome, such as diabetes, preeclampsia, oligoamnios or poliamnios, or fetal growth retardation. Only women who fulfilled all those lowrisk pregnancy requirements were considered for inclusion in the sample.

All the women in the sample gave birth to a healthy baby, a new-born whose medical input was limited to routine screening examination. From an initial pool of 390 eligible mothers, 325 women who were not planning an elective cesarean section matched all the criteria for low-risk pregnancy. Out of those 325 women who were invited to participate in the pilot project, $18(5.5 \%)$ decided not to participate and 31 (9.5\%) 
provided written consent but did not complete the questionnaires. Hence, the sample for the study comprised a total of 276 women.

\subsection{Measurements}

\subsubsection{Self-Efficacy}

Childbirth self-efficacy has been widely measured using the Childbirth Self-Efficacy Inventory (CBSEI), a self-report tool to test the ability of women to cope with the approaching childbirth experience shown to have construct validity. ${ }^{[15]}$ For this analysis, we have used the Spanish translation of the questionnaire, shown to be reliable (Cronbach's alpha in excess of .85 for all the four sub-scales of the inventory) and have construct validity as well. ${ }^{[23]}$ The instrument comprises 62 items, with responses based on a 10-point Likert-type scale distributed in two stages (corresponding to the two phases of birth: Active Labor and Second Stage). All the women were included in the sample in spite of the type of birth. Hence, to include all the C-sections from the sample of 276 women, the present study made use only of the CBSEI scales (range 15-150) for active labor. Results in the items from the self-efficacy subscales point to a woman's belief in her ability to carry on specific behaviors. The questionnaire was given again after childbirth to measure the actual use of coping behaviors in active labor. The internal consistency of the antenatal and postnatal CBSEI scales for active labor was very high: Cronbach's alpha values in excess of .85 .

\subsubsection{Satisfaction}

To measure the satisfaction with the childbirth experience, we decided to make use of some relevant items from the Mackey Satisfaction Childbirth Rating Scale (MCSRS). ${ }^{[1]}$ We examined the translation to Spanish provided by MasPons et al., ${ }^{[24]}$ who demonstrated the reliability and construct validity of the instrument. We found out that the whole scale was not suitable for $\mathrm{C}$-sections since it was designed for spontaneous vaginal birth. After several discussions with healthcare professionals and experts, we identified 6 relevant items from the literature that summarize the principal factors of the MCSRS questionnaire, and are suitable for all types of birth. Valued through a 10-point Likert scale, the six items carried information about satisfaction with the experience of becoming a mother, the whole childbirth experience, the perception of control during childbirth, the support from health care staff, the treatment received at the hospital, and the endurance of pain. The overall satisfaction measure was obtained by adding the scores on all these items (range 6-60). The internal consistency of the scale of satisfaction with the childbirth experience was high: Cronbach's alpha value of 76 .

\subsubsection{Anxiety}

We measured the level of anxiety specific to childbirth, i.e. the degree to which pregnant women experience anxiety in relation to their forthcoming birth, using a 5-item scale developed by Drummond and Rickwood ${ }^{[25]}$ for a study conducted to validate the CBSEI questionnaire in an Australian sample. Subjects were asked to indicate on a 5-point Likert scale the degree to which they experience anxiety in relation to their forthcoming birth, with higher scores indicating more intense feelings of anxiety regarding the approaching labor and delivery. The scale was shown to have internal consistency in the original Australian sample (Cronbach's alpha of 0.71 ), as well as in the present study (Cronbach's alpha of $0.73)$.

\subsubsection{Support}

Perceived support during birth from family, friends and partner was encapsulated in two direct 10-point Liker type questions, addressing specifically the level of support felt: from a partner (question 1), from friends and family (question 2).

Demographic information Age, parity, social status and educational levels.

Other postnatal information Type of birth, weight of the baby, duration of labor (in hours).

\subsection{Ethical considerations}

Ethics approval for the study was obtained from the Ethics Committee of Galicia (ref. 2013/304). Participation was voluntary; all participants gave written consent.

\subsection{Procedure}

The participants in the study were pregnant women presenting low physical and psychological risks. All the eligible women, i.e. primiparous and multiparous pregnant women within the last three months of a low-risk pregnancy, were provided with verbal and written information about the study and were then given antenatal and postnatal questionnaires with an attached information/consent sheet by their midwives. Once completed, the questionnaires were returned either through the midwife or delivered in an envelope addressed to her through the admissions desk of the corresponding health center.

\subsection{Data analysis}

Data were analyzed with IBM SPSS Statistics version 22.0. We used descriptive statistics to analyze socio-demographic and perinatal characteristics of the sample. The correlation between self-efficacy expectancies and the use of coping behaviors was tested through the Pearson's product-moment correlation coefficient between the antenatal and postnatal CBSEI total scores. The impact of previous experience in 
childbirth on levels of satisfaction with the childbirth experience was assessed by means of a one way between-groups analysis of variance. To assess the ability of the variables collected in the postnatal questionnaire to predict levels of total satisfaction after childbirth we conducted a hierarchical multiple regression analysis.

\section{FINDings}

Table 1 shows the socio-demographic and perinatal characteristics of the participants. More than $80 \%$ of the participants graduated from secondary or tertiary education programs, and over $72 \%$ of the women were employed at the time of pregnancy. The proportion of women with previous childbirth experience was $37 \%$. Most of the women in the sample (in excess of 97\%) had a stable partner at the time of birth.

Table 1. Sample-Demographics and perinatal characteristics of the participants $(n=276)$

\begin{tabular}{lll}
\hline Characteristics & $\mathbf{n}$ & \% \\
\hline Age (Average: 32.6, S.D $=4.35$, range & $=20-41)$ & \\
$\leq 30$ & 86 & 31.0 \\
$>30$ & 190 & 69.0 \\
Education & & \\
Unknown & 7 & 2.5 \\
Primary & 48 & 17.5 \\
Secondary & 108 & 38.9 \\
Tertiary & 113 & 41.1 \\
Occupation & & \\
Housewife & 78 & 27.6 \\
Employed & 198 & 72.4 \\
Parity & & \\
Primiparous & 174 & 63.0 \\
Multiparous & 102 & 37.0 \\
Type of Birth & & \\
Spontaneous Vaginal Birth & 180 & 65.2 \\
Instrumental Vaginal Birth & 49 & 17.8 \\
Cesarean Section & 47 & 17.0 \\
\hline
\end{tabular}

\subsection{Self-efficacy expectancies and coping}

Table 2 shows the prenatal CBSEI expectancies scores for active labor, as well as the postnatal CBSEI coping scores.
Mean scores of the whole sample and by type of pregnancy are shown in columns 2 to 4 of Table 2. An independent samples $t$-test was conducted to compare the scores on the CBSEI scales for primiparous and multiparous women. No statistically significant differences were found.

Columns 5 to 7 show average scores by type of birth. In vaginal birth (spontaneous and instrumental) no statistically significant differences were observed in any of the self-efficacy scales (expectancies, and conducts); on the other hand, although women with Cesarean sections present lower scores in self-efficacy and realization of coping strategies, the differences did not reach statistical significance.

To undertake the first objective of the study we examined the correlation between self-efficacy expectancies (antenatal CBSEI total scores) and coping (postnatal CBSEI total scores). The Pearson's product-moment correlation coefficient was $0.46(p<.001)$. Higher scores on the antenatal expectancy scale were associated with higher scores on the postnatal coping scale. Hence, the results stand in support of the association between self-efficacy expectancies and coping: pregnant women in the sample with larger scores in self-efficacy carried on more coping behaviors for a longer duration during active labor.

\subsection{Coping and satisfaction with childbirth experience}

To explore the impact of the type of birth on levels of satisfaction with the childbirth experience, the subjects were divided into three groups (Spontaneous Vaginal Birth, Instrumental Vaginal Birth, and Cesarean section). We then conducted a one-way between-groups analysis of variance to examine the differences in satisfaction between the three groups of women. Some statistical procedures, analysis of variance among them, assume a condition of the sample denominated homoscedasticity - equality of variances. We checked the homoscedasticity of the three groups in the sample through Levene's test. The results of the test, $\mathrm{F}(2,267)=0.17, p=$ .984 , stand in support of the equality of variances. The analysis of variance revealed a significant association $(p<.01)$ between the type of birth and levels of childbirth satisfaction (see Table 3).

Table 2. Average scores on the CBSEI expectancies and coping behavior scales

\begin{tabular}{lllllllll}
\hline & \multicolumn{2}{l}{ Type of Pregnancy } & & & \multicolumn{2}{l}{ Type of Birth } \\
\cline { 2 - 3 } & Total & Primip & Multip & & & Spont & Instrum & CS \\
\hline Number of subjects & 276 & 174 & 102 & & 180 & 49 & 47 \\
Self-efficacy expectancies & 103.7 & 120.3 & 101 & & 104.1 & 108.1 & 97.6 \\
Coping & 98.6 & 99 & 98 & & 99.6 & 99.4 & 94.4 \\
\hline
\end{tabular}


Table 3. Results of the one-way between-groups analysis of variance. Response variable: total satisfaction. Fixed factor: type of birth

\begin{tabular}{llllll}
\hline Total satisfaction & & & & & \\
& Sum of Squares & df & Mean Square & F & -value \\
\hline Between Groups & 576.9 & 2 & 288.4 & 5.56 & .004 \\
Within Groups & 13857 & 267 & 51.9 & & \\
Total & 14434 & 269 & & & \\
\hline
\end{tabular}

Despite reaching statistical significance, the difference in mean scores between groups was small. The strength of that difference, measured through eta squared, was low (.035). Post-hoc comparisons (i.e., looking at the data for a priori unspecified patterns), using Tukey's HSD test, indicated that the mean score for normal births $(\mathrm{M}=52.02, \mathrm{SD}=7.24)$ was significantly different from $\mathrm{C}$-sections $(\mathrm{M}=47.95$, $\mathrm{SD}$ $=7.84$ ). There were no statistically significant differences in mean scores neither between spontaneous and instrumental vaginal births nor between instrumental vaginal births and C-sections.

To undertake the second objective of the study, we conducted a hierarchical multiple regression analysis to assess the ability of the variables collected in the postnatal questionnaire to predict levels of total satisfaction after childbirth. Preliminary analyses were conducted to ensure no violation of the multiple regression assumptions of normality, linearity and homoscedasticity. In the sample of women with low obstetric, psychological and social risk, all women had a healthy baby (inclusion criterion), good support from the partner and low anxiety.

Significant associations were found between levels of total satisfaction and three of the variables: coping, support from a partner, and anxiety. In the regression analysis, coping during childbirth was entered at step 1, explaining $25 \%$ of the variance in the total satisfaction levels. Support from a partner, entered at step 2, increased the explanation of the variance in $4 \%$. After entry of anxiety at step 3 the total variance explained by the model was $32 \%, \mathrm{~F}(3,264)=40.380$, $p<.001$. The results from the analysis confirm the statistically significant association between coping and satisfaction after childbirth. Table 4 presents the complete results of the regression analysis.

Table 4. Hierarchical regression analysis: Prediction of levels of total satisfaction after childbirth

\begin{tabular}{|c|c|c|c|c|c|c|c|}
\hline & & B & SE B & Beta & $p$-value & $R^{2}$ & $R^{2}$ change \\
\hline \multirow{2}{*}{1} & (Constant) & 34.741 & 1.775 & & $p<.001$ & \multirow{2}{*}{0.252} & \multirow{2}{*}{0.252} \\
\hline & Coping & 0.166 & 0.017 & 0.502 & $p<.001$ & & \\
\hline \multirow{3}{*}{2} & (Constant) & 26.31 & 2.754 & & $p<.001$ & \multirow{3}{*}{0.293} & \multirow{3}{*}{0.041} \\
\hline & Coping & 0.162 & 0.017 & 0.49 & $p<.001$ & & \\
\hline & Support & 0.944 & 0.24 & 0.203 & $p<.001$ & & \\
\hline \multirow{4}{*}{3} & (Constant) & 30.326 & 3.056 & & $p<.001$ & \multirow{4}{*}{0.315} & \multirow{4}{*}{0.021} \\
\hline & Coping & 0.15 & 0.017 & 0.454 & $p<.001$ & & \\
\hline & Support & 0.884 & 0.238 & 0.191 & $p<.001$ & & \\
\hline & Anxiety & -0.421 & 0.147 & -0.151 & $p=.004$ & & \\
\hline
\end{tabular}

Note. Response variable: Total satisfaction

The results of the analysis of the sample support the prediction based on the self-efficacy theory, ${ }^{[26]}$ namely women with high self-efficacy use more coping behaviors throughout labor, while women with low self-efficacy expectancies present a deficit in the ability to cope with pain. In addition, since we have not found any statistically meaningful association between the use of coping behavior strategies and the duration of labor, we are inclined to conclude that what makes a woman in labor to use coping behavior strategies is her perception of being able to cope with pain.

\section{Discussion}

This study has contributed to further understanding the association between self-efficacy expectancies and coping with women's satisfaction in childbirth. The results from this study indicate that high scores in self-efficacy expectancies and the use of coping behaviors in active labor were associated with a good childbirth experience. Women with a 
positive attitude towards childbirth, who also believe in their ability for coping with pain, are not afraid of giving birth. Those women struggle to maintain control, and use all resources in their hand to end up in a spontaneous vaginal birth; they also make more and longer use of coping behaviors, leading to a better experience. Besides, even in the case of difficult births involving instrumental intervention, therefore requiring medical help, we have found that high scores in self-efficacy were associated with a more positive experience.

The findings tie well into the existing literature on birth satisfaction. Fair and Morrison report that experienced control during labor and birth is an important predictor of birth satisfaction. ${ }^{[27]}$ Berentson-Shaw et al. found that a stronger self-efficacy predicted increased birth satisfaction. ${ }^{[28]}$ On the other hand, Spaich et al. report that the mode of delivery does not directly influence women's satisfaction with childbirth. ${ }^{[20]}$ Hodnett reports that "the influences of pain, pain relief, and intrapartum medical interventions on subsequent satisfaction are neither as obvious, as direct, nor as powerful as the influences of the attitudes and behaviors of the caregivers" ${ }^{[29]}$ All those results are in line with the findings of this study.

In the process of becoming a mother, the perception of the childbirth experience is a key element to ensure a proper care of the new being and the establishment of adequate bonding. A positive childbirth experience has been associated with giving birth to healthy babies, good psychological support, pain relief and high self-efficacy; ${ }^{[30]}$ data from this study support these connections.

As regards the implications for practice, Tilden et al. reported that childbirth self-efficacy is a psychosocial factor that can be modified through various efficacy-enhancing interventions. ${ }^{[31]}$ Moreover, a prospective cohort study involving more than six hundred Canadian women found that enhancement of patient awareness, relaxation, and control, a predictor of a quality birth experience, was amenable to nursing interventions. ${ }^{[32]}$ Brixval et al. examined the effect of an antenatal education program in small classes in a randomized control trial, using a questionnaire that covers "essential elements of childbirth self-efficacy, i.e. confidence in own ability to cope with labor in the latent phase of labor and ability to cope with the birth process". ${ }^{[33]}$ The results from the trial indicate that "attending a structured antenatal education program in small classes may increase confidence in own ability to cope at home during labor and confidence in own ability to handle the birth process".

On the impact of antenatal education on childbirth outcomes, the literature offers an array of mixed results. Artieta-Pinedo et al. analyzed the benefits of antenatal education for the childbirth process in a sample of 616 women from Northern Spain. ${ }^{[34]}$ Although they reported that women who had attended antenatal education classes experienced less anxiety during birth than those who had not, they did not find any significant association between antenatal education and benefits during childbirth. However, Fair and Morrison report on the positive effects of the collaboration between health care providers and the women they care for to use techniques that maximize the experience of control, especially during labor and birth. ${ }^{[27]}$ Hollins Martin and Robb report that women perceive more value in education critical to their outcomes, "in relation to delivery of education, midwives require to make purpose and links clear". ${ }^{[35]}$ Maimburg et al. report that a good birth experience in the long term is more likely when attending a structured antenatal program and if medical intervention is avoided during birth. ${ }^{[36]}$

It seems clear that self-efficacy is a psychological trait that can be enhanced through structured maternal education. Besides, although more research is needed to assess the impact of antenatal education on childbirth satisfaction, the literature offers some evidence in support of the association between structured maternal education and a satisfactory birth experience.

\subsection{Limitations}

The analysis reported in this paper constitutes a preliminary study that calls for more extensive research in the area. In particular, the sample size might not be large enough to generalize the results to other populations, making it necessary to carry out similar investigations in other health areas.

The study is observational and as such only associations between variables were described. Postpartum data were collected prospectively and therefore constitute a reminder of past experience.

Women who participated in the study had all low-risk pregnancies; all of them expressed their preference for a physiological birth. On the other hand, all the women belong to the same metropolitan area, so the sample may not be representative of other populations.

Participation in this study was completely voluntary, hence women who responded to the questionnaires may differ in their motivation and attitude toward childbirth from women who did not agree to participate.

Midwives who participated in this study are firm and enthusiastic advocates of natural childbirth, who train and encourage their patients in using coping behaviors during childbirth; they may therefore not be representative of the attention paid to public health in terms of professional support and 
stimulation to use coping behaviors in childbirth.

\subsection{Implications for practice}

The findings of this study have implications for midwifery, particularly for those professionals in primary care who actively engage in maternal education. It may also help in better inform the job of professionals who take care of women in the hospital during labor.

The CBSEI questionnaire has been shown to be reliable and presents construct validity in its original format as well as in the translated version used in this study. As such, it could be a useful tool to assess the level of confidence women have in their ability to cope with the painful experience of childbirth. It could also help in identifying pregnant women who will not face a spontaneous vaginal birth.

Given the association found between Self-efficacy and coping with childbirth satisfaction, it would be advisable to enhance self-efficacy in pregnant women through maternal education courses, in which they receive information about the physiology of birth, on protocols and routine procedures, and about different options in analgesia. In combination with physical training, breathing exercises and relaxation practice, support from partner and encouragement of professionals, both during pregnancy and childbirth, self-efficacy can contribute to increasing the perceived ability of control, thus encouraging the realization of coping behaviors that will contribute to increasing the satisfaction with childbirth experience.

\section{Conclusions}

In the present study, we have found that antenatal selfefficacy beliefs were strongly correlated with the use of coping behaviors during childbirth. We have also found that coping was associated with the ability to endure pain, with a positive perception of the experience of childbirth and greater levels of satisfaction with motherhood.

The results of the study help in further understanding the relationship between self-efficacy and the childbirth experience, adding to the limited body of knowledge about childbirth satisfaction, self-efficacy and midwifery. Through the scores in the self-efficacy scales, it is possible to predict which women would benefit from additional education and more support during pregnancy to be better prepared for childbirth. Hence, the study supports the need for improving self-efficacy, for reporting the benefits of the use of coping behaviors during childbirth, for adequate training during pregnancy, and last but not least, for midwives to encourage the use of coping behaviors during childbirth.

\section{ACKNOWLEDGEMENTS}

We wish to thank the midwives who collaborated in the study for their time and their suggestions administering the questionnaires. We are also very grateful to all the women who participated in the study.

\section{CONFLICTS OF INTEREST DisClosure}

The authors declare no conflict of interest.

\section{REFERENCES}

[1] Goodman P, Mackey MC, Tavakoli AS. Factors related to childbirth satisfaction. Journal of Avanced Nursing. 2004; 46(2): 212-219. http://dx.doi.org/10.1111/j.1365-2648.2003.02981.x

[2] Bélanger-Lévesque M, Pasquier M, Roy-Matton N, et al. Maternal and paternal satisfaction in the delivery room: a cross-sectional comparative study. BMJ Open. 2014; 4: e004013. http://dx. doi .org /10.1136/bmjopen-2013-004013

[3] Michels A, Kruske S, Thomson R. Women's postnatal psychological functioning: The role of satisfaction with intrapartum care and the birth experience. Journal of Reproductive and Infant Psychology 2013; 31(2): 172-182. http://dx.doi.org/10.1080/0264683 8.2013.791921

[4] Bell AF, Anderson E. The birth experience and women's postnatal depression: A systematic review. Midwifery. 2016; 39: 112-123. http://dx.doi.org/10.1016/j.midw. 2016.04.014

[5] Sockol LE, Battle CL, et al. Correlates of impaired mother-infant bonding in a partial hospital program for perinatal women. Archives of Women's Mental Health. 2014; 17(5): 465-469. http://dx.doi .org/10.1007/s00737-014-0419-6

[6] Smith CA, Levett KM, et al. Relaxation techniques for pain management in labour. Cochrane Database Syst Rev. 2011; 7(12). http:
//dx.doi.org/10.1002/14651858.CD009514

[7] Nilsson C, Lundgren I, Karlström A, et al. Self reported fear of childbirth and its association with women's birth experience and mode of delivery: a longitudinal population-based study. Women Birth. 2012; 25(3): 114-121. http://dx.doi.org/10.1016/j. wombi. 2011. 06.001

[8] Rooks JP. Labor Pain Management Other Than Neuraxial: What Do We Know and Where Do We Go Next? Birth-Issued in Perinatal Care. 2012; 39(4): 318-322. http://dx.doi.org/10.1111/bir t.12009

[9] Avery MD, Saftner MA, Larson B, et al. A systematic review of maternal confidence for physiologic birth: characteristics of prenatal care and confidence measurement. Journal of Midwifery \& Women's Health. 2014; 59(6): 586-595. http://dx.doi.org/10.1111/j mwh. 12269

[10] Guardino CM, Schetter CD. Coping during pregnancy: a systematic review and recommendations. Health Psychological Review. 2014; 8(1): 70-94. http://dx.doi.org/10.1080/17437199.2012.7 52659

[11] Escott D, Slade P, Spiby H. Preparation for pain management during childbirth: the psychological aspects of coping strategy development 
in antenatal education. Clinical Psychology Review. 2009; 29(7): 617-622. http://dx.doi.org/10.1016/j.cpr.2009.07.002

[12] Bandura A. Self-Efficacy, toward a unifying theory of behavioral change. Psychological Review. 1977; 84(2): 191-215. https : //do i. org/10.1016/0146-6402 (78) 90002-4

[13] Tilden EL, Caughey AB, et al. The Effect of Childbirth Self-Efficacy on Perinatal Outcomes. Journal of Obstetric, Gynecologic \& Neonatal Nursing. 2016; 45(4): 465-480. http://dx. doi .org/10.1016 /j.jogn.2016.06.003

[14] Manning MM, Wright TL. Self-efficacy expectancies, outcome expectancies, and the persistence of pain control in childbirth. Journal of Personality and Social Psychology. 1983; 45(2): 421-431. http://dx.doi.org/10.1037/0022-3514.45.2.421

[15] Lowe NK. Maternal confidence for labor: Development of the Childbirth Self-Efficacy Inventory. Research in Nursing \& Health. 1993; 16(2): 141-149. http://dx.doi.org/10.1002/nur. 477016020 9

[16] Lowe NK. The nature of labor pain. American Journal of Obstetrics and Gynecology. 2002; 186(5 Suppl Nature): S16-24. https: //doi.org/10.1016/S0002-9378(02)70179-8

[17] Sinclair M, O'Boyle C. The Childbirth Self-Efficacy Inventory: a replication study. Journal of Advanced Nursing. 1999: 30(6): 14161423. http://dx.doi.org/10.1046/j.1365-2648.1999.012 $30 . x$

[18] Salomonsson B, Gullberg MT, et al. Self-efficacy beliefs and fear of childbirth in nulliparous women. Journal of Psychosomatic Obstetrics \& Gynecology. 2013; 34(3): 116-121. http://dx.doi.org/1 $0.3109 / 0167482 X .2013 .824418$

[19] Schwartz L, Toohill J, Creedy DK, et al. Factors associated with childbirth self-efficacy in Australian childbearing women. BMC Pregnancy \& Childbirth. 2015; 15: 29. https ://doi .org/10.118 6/s12884-015-0465-8

[20] Spaich S, Welzel G, Berlit S, et al. Mode of delivery and its influence on women's satisfaction with childbirth. European Journal of Obstetrics \& Gynecology and Reproductive Biology. 2013; 170(2): 401-406. http://dx.doi.org/10.1016/j.ejogrb. 2013.07.040

[21] Dilks F, Beal J. Role of self-efficacy in birth choice. Journal of Perinatal \& Neonatal Nursing. 1997; 11(1): 1-9. https://doi .org/10 $.1097 / 00005237-199706000-00003$

[22] Taheri Z, Mazaheri MA, Khorsandi M, et al. Effect of Educational Intervention on Self-efficacy for Choosing Delivery Method among Pregnant Women in 2013. International Journal of Preventive Medicine. 2013; 5(10): 1247-1254. http://jech.umsha.ac.ir /article-1-42-en.html

[23] Cunqueiro MJ, Comeche MI, Docampo D. Childbirth Self-Efficacy Inventory: psychometric testing of the Spanish version. Journal of Advanced Nursing. 2009; 65(12): 2710-2718. http://dx.doi.o $\mathrm{rg} / 10.1111 / \mathrm{j} .1365-2648.2009 .05161 . \mathrm{x}$
[24] Mas-Pons R, Barona-Vilar C, Carreguí-Vilar S, et al. Satisfacción de las mujeres con la experiencia del parto: validación de la Mackey Satisfaction Childbirth Rating Scale. Gaceta Sanitaria. 2012; 26(3): 236-242. https://doi.org/10.1016/j.gaceta. 2011.09.019

[25] Drummond J, Rickwood D. Childbirth confidence: validating the Childbirth Self-Efficacy Inventory (CBSEI) in an Australian sample. Journal of Advanced Nursing. 1997; 26(3): 613-622. https : //doi.org/10.1046/j.1365-2648.1997.t01-24-00999.x

[26] Bandura A. Self-efficacy: The Exercise of Control. W.H. Freeman, New York: 1997.

[27] Fair CD, Morrison TE. The relationship between prenatal control, expectations, experienced control, and birth satisfaction among primiparous women. Midwifery. 2012; 28(1): 39-44. http://dx.doi.o $\mathrm{rg} / 10.1016 / \mathrm{j}$.midw. 2010.10.013

[28] Berentson-Shaw J, Scott KM, Jose PE. Do self-efficacy beliefs predict the primiparous labour and birth experience? A longitudinal study. Journal of Reproductive and Infant Psychology. 2009; 27(4): 357-373. http://dx.doi.org/10.1016/j.jogn.2016.06.003

[29] Hodnett ED. Pain and women's satisfaction with the experience of childbirth: a systematic review. American Journal of Obstetrics and Gynecology. 2002; 186 (5 Suppl Nature): S160-172. http://dx.doi.org/10.1016/S0002-9378(02)70189-0

[30] Gau ML, Chang CY, et al. Effects of birth ball exercise on pain and self-efficacy during childbirth: a randomised controlled trial in Taiwan. Midwifery. 2011; 27(6): 293-300. http://dx.doi.org/10. 1016/j.midw. 2011.02.004

[31] Simkin P, Stewart M, Shearer B, et al. The language of birth. Birth 2012; 39(2): 156-164. http://dx.doi.org/10.1111/j.1523-5 $36 \mathrm{X} .2012 .00535 . \mathrm{x}$

[32] Bryanton J, Gagnon AJ, et al. Predictors of women's perceptions of the childbirth experience. Journal of Obstetric Gynecologic \& Neonatal Nursing. 2008; 37(1): 24-34. http://dx.doi.org/10. $1111 / j .1552-6909.2007 .00203 . x$

[33] Brixval CS, Axelsen SF, Thygesen LC, et al. Antenatal education in small classes may increase childbirth self-efficacy: Results from a Danish randomised trial. Sexual \& Reproductive Healthcare. 2016; 10: 32-34. http://dx.doi.org/10.1016/j.srhc.2016.03.00 3

[34] Artieta-Pinedo I, Paz-Pascual C, Grandes G, et al. The Benefits of Antenatal Education for the Childbirth Process in Spain. Nursing Research. 2010; 59(3): 194-202. http://dx.doi.org/10.1097 /NNR. 0b013e3181dbbb4e

[35] Hollis Martin CJ, Robb Y. Women's views about the importance of education in preparation for childbirth. Nurse Educ Pract. 2013 Nov; 13(6): 512-8. http://dx.doi.org/10.1016/j.nepr.2013.02. 013

[36] Maimburg RD, Vaeth M, Dahlen H. Women's experience of childbirth - A five year follow-up of the randomised controlled trial "Ready for Child Trial" birth. Women and Birth. 2016; 29(5): 450-454. http://dx.doi.org/10.1016/j.wombi.2016.02.003 